\title{
PSEUDOPOTENTIAL SCF-MO STUDIES OF HYPERVALENT COMPOUNDS
}

Part III. $\mathrm{I}_{2}, \mathrm{IF}, \mathrm{IF}_{3}$ and $\mathrm{IF}_{5}$

\section{S. BARTELL}

Department of Chemistry, University of Michigan, Ann Arbor, Michigan 48103 (U.S.A.)

A. GAVEZZOTTI

Istituto di Chimica Fisica, Università degli Studi di Milano, Milan (Italy)

(Received 22 March 1982)

\begin{abstract}
The (ab initio) effective potential method developed previously has been applied to several molecules in order to establish a basis set and effective potential for iodine and to examine aspects of the potential surfaces of hypervalent compounds of iodine. Implied lone-pair stereochemical activity is found to agree well with experiment. Results for the structures and force constants closely resemble those found in related studies of xenon fluorides which exhibit similar systematic deviations from experiment. Iodine-fluorine bond lengths are overestimated by about $0.05 \AA$ and stretching force constants are slightly too high. These data provide a consistent basis for investigating further aspects of hypervalent iodine compounds that have so far resisted experimental resolution.
\end{abstract}

\section{INTRODUCTION}

Although the chemistry of hypervalent compounds of iodine has been extensively explored, the physical characterization of the compounds has been sketchy and the theoretical treatment limited mainly to semiempirical quantum methods $[1-4]$. Because of the significant gaps remaining in our understanding of these important but experimentally and theoretically elusive compounds, it secmed worthwhilc to apply pseudopotential theory to their study. This ab initio molecular orbital approach, recently developed by Ewig and co-workers [5-7] and others [8,9] into a practical technique applicable to polyatomic molecules, is particularly suitable for molecules containing heavy atoms, for which all-electron computations are prohibitively expensive. Of special interest is the molecule $\mathrm{IF}_{7}$ whose properties have yet to be interpreted conclusively. Before tackling this comparatively complex case, however, it was necessary to develop a basis set and effective potentials and to test them on simpler examples in order to assess the systematic deviations between these and experiment which might be expected. In earlier, closely related work $[10,11]$ the systems $F_{2} \cdots F_{2}$ and a series of 
xenon fluorides were treated. In the present study, the structures and some aspects of the potential surfaces of $\mathrm{I}_{2}, \mathrm{IF}, \mathrm{IF}_{3}$ and $\mathrm{IF}_{5}$ are examined.

\section{PROCEDURE}

The computational method is described in Part I [10] and in earlier publications by Ewig and co-workers [5-7]. It is a fully ab initio LCAO-MO SCF procedure which introduces a molecular Phillips-Kleinman pseudopotential operator into the Fock equations together with a non-empirical frozen-core model potential thus making it possible to perform valence-only variational computations. In the present work calculations are carried out using minimal basis sets. Contracted Gaussian basis functions were constructed for iodine by procedures discussed in Part I, modelling them after the single zeta core and double zeta valence atomic orbitals of Clementi et al. [12] . The resultant iodine $5 s$ and $5 p$ basis functions are listed in Table 1 . Associated local potentials are presented in Table 2. Fluorine functions are those listed in Part I.

In the case of the diatomic molecules IF and $\mathrm{I}_{2}$, calculations of the electronic energy were carried out at several internuclear distances $(3,3.5,3.75$, 4 and 4.25 au for IF and 4, 4.5, 5, 5.25, 5.5 and 6.0 au for $\mathrm{I}_{2}$ ). Bond lengths and force constants were determined by incorporating the four points of lowest energy in a cubic polynomial. For the sake of comparison, the frequencies were calculated from the second derivative of the potential energy evaluated at the internuclear distances corresponding to both the calculated potential minimum and the experimental potential minimum.

\section{RESULTS}

Calculated orbital energies, bond lengths and stretching frequencies are recorded in Table 3 for the molecules $\mathrm{IF}$ and $\mathrm{I}_{2}$. Corresponding all-electron SCF results $[13,14]$ and experimental values $[15-20]$ are also included for comparison.

Because a gradient procedure for efficient geometric optimization was not incorporated into the calculations, results for the polyatomic molecules $\mathrm{IF}_{3}$ and $\mathrm{IF}_{5}$ are more fragmentary. Of particular interest were the angles between

\section{TABLE 1}

Contraction coefficients and Gaussian exponents for iodine valence basis functions

\begin{tabular}{|c|c|c|c|}
\hline \multicolumn{2}{|l|}{$5 s$} & \multicolumn{2}{|l|}{$5 p$} \\
\hline Coefficient & Exponent & Coefficient & Exponent \\
\hline 0.009377 & 8.02105 & -0.090175 & 1.75520 \\
\hline-0.356036 & 1.30748 & 0.476071 & 0.36927 \\
\hline 0.675111 & 0.30455 & 0.451520 & 0.15034 \\
\hline 0.535511 & 0.12368 & 0.196275 & 0.078604 \\
\hline
\end{tabular}




\section{TABLE 2}

Coefficients and exponents for the Gaussian expansion ${ }^{\text {a }}$ of the local potentials $\left(w^{i}\right)$ for iodine

\begin{tabular}{|c|c|c|c|}
\hline \multicolumn{2}{|l|}{$5 s$} & \multicolumn{2}{|l|}{$5 p$} \\
\hline Coefficient & Exponent & Coefficient & Exponent \\
\hline-0.051512 & 13.49673 & -0.197594 & 10.34314 \\
\hline-0.091914 & 6.98187 & 0.292426 & 3.10014 \\
\hline 0.240001 & 3.52696 & 0.066050 & 1.85731 \\
\hline 0.184311 & 1.87125 & 0.071512 & 1.61103 \\
\hline 0.185245 & 0.51536 & 0.013740 & 0.64246 \\
\hline-0.169636 & 0.50397 & 0.002469 & 0.15088 \\
\hline 0.001756 & 0.10686 & 0.000266 & 0.00149 \\
\hline
\end{tabular}

${ }^{a}$ The form of the expansion is defined by eqn. (23) of ref. 10 .

apical and basal bonds* which are considered to be indicators of the degree of stereochemical activity of the iodine lone pairs. It was assumed at the outset that the symmetries of $\mathrm{IF}_{3}$ and $\mathrm{IF}_{5}$ are $C_{2 \mathrm{v}}$ and $C_{4 \mathrm{v}}$ respectively. In the case of $\mathrm{IF}_{3}$, the mean bond length was optimized approximately by fixing $\angle \mathrm{F}_{\mathrm{ap}}-\mathrm{I}-\mathrm{F}_{\mathrm{ba}}$ at $85^{\circ}$ and constraining the basal bond length to exceed

\section{TABLE 3}

Orbital energies ${ }^{a}$, ionization potentials, bond lengths and vibrational frequencies for IF and $\mathrm{I}_{2}$

\begin{tabular}{|c|c|c|c|c|c|c|c|c|}
\hline \multirow[t]{2}{*}{ Orbital } & \multicolumn{3}{|l|}{ IF } & \multirow[t]{2}{*}{ Orbital } & \multicolumn{4}{|l|}{$\mathrm{I}_{2}$} \\
\hline & $\overline{\mathrm{DZ}}+\mathbf{p b}$ & This work & Expt. & & $\mathrm{H}-\mathrm{F}^{\mathrm{c}}$ & $\mathrm{Szb}$ & This work & Expt. \\
\hline$a_{1}$ & -1.5902 & -1.5400 & -- & $\sigma_{g}$ & -0.9167 & -0.8485 & -0.8520 & - \\
\hline$a_{1}$ & -0.8693 & -0.8182 & -- & $\sigma_{\mathbf{u}}^{\mathrm{g}}$ & -0.7885 & -0.7092 & -0.7351 & - \\
\hline$e_{1}$ & -0.6805 & -0.6391 & $0.5858^{d}$ & $\pi u$ & -0.4439 & -0.3952 & -0.4179 & $0.4146^{\mathrm{e}}$ \\
\hline$a_{1}$ & -0.6346 & -0.5470 & 0.5593 & $\sigma_{\mathbf{g}}$ & -0.4718 & -0.4253 & -0.4123 & 0.4700 \\
\hline$e_{1}$ & -0.3877 & -0.3764 & 0.4032 & $\pi_{\mathrm{g}}^{\mathrm{s}}$ & -0.3623 & -0.3098 & -0.3599 & 0.3543 \\
\hline$r(\AA)^{f}$ & 1.826 & 1.852 & -- & & 2.678 & 2.667 & 2.646 & - \\
\hline$r_{\min }(A)$ & 1.86 & 1.957 & $1.909 \mathrm{~g}$ & & 2.678 & 2.59 & 2.790 & $2.667^{\mathrm{h}}$ \\
\hline$\nu\left(\mathrm{cm}^{-1}\right)$ & 711 & $673(726)^{\mathrm{i}}$ & $610^{j}$ & & 236 & 290 & $232(271)^{i}$ & $214.6^{\mathrm{k}}$ \\
\hline
\end{tabular}

${ }^{\mathrm{a}}$ Energy in hartree. ${ }^{\mathrm{b}}$ Ref. $13 .{ }^{\mathrm{c}}$ Ref. $14{ }^{\mathrm{d}}$ Ref. $15 .{ }^{\mathrm{e}}$ Ref. 16 . Average of spin-orbit split values. ${ }^{\text {f } I n t e r n u c l e a r ~ d i s t a n c e ~ a t ~ w h i c h ~ l i s t e d ~ v a l u e s ~ w e r e ~ c a l c u l a t e d . ~}{ }^{\mathrm{g}} \mathrm{Ref} .17{ }^{\mathrm{h}} \mathrm{Ref} .18$. iValues in parentheses correspond to calculated force constants at experimental $r_{\mathrm{e}}$ values; those not in parentheses correspond to calculated force constants at calculated $r_{\text {min }}$ values. ${ }^{\mathrm{j}}$ Ref. $19 .{ }^{\mathrm{k}}$ Ref. 20.

\footnotetext{
* For the purpose of discussion it is helpful to introduce a nomenclature to distinguish between the two characteristically different types of IF bonds encountered in polyatomic molecules. The nominally normal single bonds found on the symmetry axes of $\mathrm{IF}_{3}$ and $\mathrm{IF}_{5}$ are designated as apical. Basal bunds, on the other hand, closely resembling those in neutral xenon fluorides or the anions $\mathrm{IF}_{2}{ }_{2}^{-}$and $\mathrm{IF}_{4}{ }^{-}$, are the bonds approximately perpendicular to the apical bonds.
} 
the apical length by $0.1 \AA$. A minimum in total valence energy, $F_{\mathrm{VT}}$, was found at $r\left(\mathrm{I}-\mathrm{F}_{\mathrm{ap}}\right)=1.905$ and $r\left(\mathrm{I}-\mathrm{F}_{\mathrm{ba}}\right)=2.005 \AA$. Then $\angle \mathrm{F}_{\mathrm{ap}}-\mathrm{I}-\mathrm{F}_{\mathrm{ba}}$ was varied, holding the apical and basal bond lengths, respectively, at 2.0 and $1.9 \AA$, until the equilibrium angle was found to be $78.6^{\circ}$ subject to the imposed constraints. In calculations upon $\mathrm{IF}_{5}$ only $\angle \mathrm{F}_{\mathrm{ap}}-\mathrm{I}-\mathrm{F}_{\mathrm{ba}}$ was varied. Bond lengths were set at the experimental values of $r\left(\mathrm{I}-\mathrm{F}_{\mathrm{ap}}\right)=1.84 \AA$ and $r\left(\mathrm{I}-\mathrm{F}_{\mathrm{ba}}\right)=1.87 \AA$. A minimum in $E_{\mathrm{VT}}$ occurred at an angle of $80.3^{\circ}$. Calculated orbital energies and $E_{\mathrm{VT}}$ values for $\mathrm{IF}_{3}$ and $\mathrm{IF}_{5}$ are presented in Tables 4 and 5.

\section{DISCUSSION}

Orbital energies for IF and $\mathrm{I}_{2}$ computed by the pseudopotential method are similar to those obtained in all-electron SCF-MO calculations (doublezeta plus polarization [13], near Hartree-Fock [14] and others [7]) and as close to the experimental ionization potentials $[15,16]$ derived from photoelectron spectra as would be expected. Our results for IF, corroborated as mentioned above, and for $\mathrm{IF}_{3}$ and $\mathrm{IF}_{5}$, which have received scant treatment by ab initio methods, are quite different from those reported by Rode [21] who carried out all-electron SCF-MO calculations based on Gaussianlobe orbitals. We have no explanation to offer for the differences. Because Rode's work determined no geometric parameters, we shall not refer to it again.

Our diatomic internuclear distances and vibrational frequencies depart little further from the observed values than do the results of all-electron singleconfiguration calculations with appreciably more flexible basis sets. Analogous comparisons are not available, theoretically or experimentally, for $\mathrm{IF}_{3}$ which polymerizes in the solid state and disproportionates before melting as the temperature is raised [22]. Enough was known about the related molecules $\mathrm{XF}, \mathrm{XF}_{3}$ and $\mathrm{XF}_{5}(\mathrm{X}=\mathrm{Cl}, \mathrm{Br}, \mathrm{I})$ to allow Deb and Coulson [1] to make a reasonable prediction for the structure of the missing member $\mathrm{IF}_{3}$. These authors suggested $1.80 \AA$ for $I F_{a p}$ and $1.90 \AA$ for $I F_{b a}$, estimates which are consistent with our results when the systematic excesses of the order of $0.1 \AA$ in IF and related $\mathrm{XeF}$ bond lengths $[10,11]$ are taken into account.

\section{TABLE 4}

Orbital energies (hartree) for $\mathrm{IF}_{3}{ }^{\mathrm{a}}$

\begin{tabular}{llllll}
\hline$a_{1}$ & -1.5506 & $b_{2}$ & $-0.6586(\pi)$ & $b_{1}$ & -0.5342 \\
$a_{1}$ & -1.4584 & $a_{1}$ & -0.6383 & $a_{1}$ & -0.5301 \\
$b_{1}$ & -1.4570 & $b_{1}$ & -0.6010 & $b_{2}$ & $-0.4374(\pi)$ \\
$a_{1}$ & -0.9254 & $b_{2}$ & $-0.5807(\pi)$ & $a_{1}$ & -0.4138 \\
$b_{1}$ & -0.6664 & $a_{2}$ & $-0.5594(\pi)$ & & \\
\hline
\end{tabular}

${ }^{\mathrm{a}} C_{2 \mathrm{v}}$ structure, $r_{\mathrm{ap}}=1.9 \AA, r_{\mathrm{ba}}=2.0 \AA$ (see footnote on $\mathrm{p} .333$ ), $\angle \mathrm{F}_{\mathrm{ap}}-\mathrm{I}-\mathrm{F}_{\mathrm{ba}}=77^{\circ}$ for this computation. 
TABLE 5

Orbital energies (hartree) for $\mathrm{IF}_{5}{ }^{\mathrm{a}}$

\begin{tabular}{llllll}
\hline$a_{1}$ & -1.6122 & $a_{1}$ & -0.7548 & $e$ & -0.5922 \\
$a_{1}$ & -1.5609 & $e$ & -0.6614 & $a_{1}$ & -0.5842 \\
$e$ & -1.5505 & $b_{2}$ & -0.6450 & $b_{1}$ & -0.5407 \\
$b_{1}$ & -1.5374 & $b_{1}$ & -0.6188 & $a_{1}$ & -0.4139 \\
$a_{1}$ & -1.0240 & $e$ & -0.6120 & & \\
$e$ & -0.7661 & $a_{2}$ & -0.5933 & & \\
\hline
\end{tabular}

${ }^{\mathrm{a}} C_{4 \mathrm{~V}}$ structure, $r_{\mathrm{ap}}=1.84 \AA, r_{\mathrm{ba}}=1.87 \AA$ (see footnote on $\mathrm{p} .333$ ), $\angle \mathrm{F}_{\mathrm{ap}}-\mathrm{I}-\mathrm{F}_{\mathrm{ba}}=85^{\circ}$ for this computation.

Our calculated value of $78.6^{\circ}$ for the angle $\mathrm{F}_{\mathrm{ap}}-\mathrm{I}-\mathrm{F}_{\mathrm{ba}}$ in $\mathrm{IF}_{3}$ is a few degrees smaller than the corresponding experimental values of $86.2^{\circ}$ [23] and $87.3^{\circ}$ [24] in $\mathrm{BrF}_{3}$ and $\mathrm{ClF}_{3}$, although the deviation is in the direction expected by the popular valence shell electron pair repulsion (VSEPR) model. The calculated angle is similar to the corresponding pseudopotential angles of $80.3^{\circ}$ in $\mathrm{IF}_{5}$ and $80.8^{\circ}$ in $\mathrm{XeF}_{5}{ }^{+}$[11]. Our value for $\mathrm{IF}_{5}$, in turn, is close to the $83.05 \pm 0.6^{\circ}$ [25] $85.1 \pm 0.4^{\circ}$ [26] and $86 \pm 1.5^{\circ}$ [27] values for $\mathrm{IF}_{5}, \mathrm{BrF}_{5}$ and $\mathrm{ClF}_{5}$ respectively, obtained from experiment. In both $\mathrm{IF}_{3}$ and $\mathrm{IF}_{5}$, then, the stereochemical activity of the lone pair embodied in the VSEPR model and revealed by the spontaneous migration of all fluorines to sites of the same side of the basal plane through the iodine atom, is well represented by the pseudopotential calculations. This work, together with more extensive work on xenon fluorides $[10,11]$, shows that the qualitative aspects of the molecular force fields of hypervalent compounds are satisfactorily accounted for by the pseudopotential approach ignoring $d$ orbitals. Moreover, the quantitative deficiencies to be expected in calculated structures and frequencies have now been mapped out. Therefore it appears promising to apply the method to our original goal [28] of attempting to understand $\mathrm{IF}_{7}$ and to resolve the contradictory interpretations of its properties.

\section{ACKNOWLEDGEMENTS}

This work was carried out at the University of Michigan while one of us (A. G.) was on leave of absence from the University of Milan. It was supported by a grant from the National Science Foundation. We thank Professors Carl S. Ewig and John R. Van Wazer for providing the computer codes needed as well as for valuable assistance and advice. We are indebted to Dr. Michael J. Rothman for his considerable help. We gratefully acknowledge computing time made available by the University of Michigan Computing Center. 


\section{REFERENCES}

1 B. M. Deb and C. A. Coulson, J. Chem. Soc. A, (1971) 958.

2 E. H. Wiebenga and D. Kracht, Inorg. Chem., 8 (1969) 738.

3 E. H. Wiebenga, E. E. Havinga and K. H. Boswijk, Adv. Inorg. Chem. Radiochem., 3 (1961) 91.

4 L. S. Bartell, Inorg. Chem., 5 (1966) 1635.

5 P. Coffey, C. S. Ewig and J. F. Van Wazer, J. Am. Chem. Soc., 97 (1975) 1656.

6 C. S. Ewig and J. R. Van Wazer, J. Chem. Phys., 63 (1975) 4035.

7 C. S. Ewig, R. Osman and J. R. Van Wazer, J. Chem. Phys., 66 (1977) 3557.

8 P. A. Christiansen, Y. S. Lee and K. S. Pitzer, J. Chem. Phys., 71 (1979) 4445.

9 W. C. Ermler, Y. S. Lee, K. S. Pitzer and N. W. Winter, J. Chem. Phys., 69 (1978) 976.

10 L. S. Bartell, M. J. Rothman, C. S. Ewig and J. R. Van Wazer, J. Chem. Phys., 73 (1980) 367 .

11 M. J. Rothman, L. S. Bartell, C. S. Ewig and J. R. Van Wazer, J. Chem. Phys., 73 (1980) 375 .

12 E. Clementi, D. L. Raimondi and W. P. Reinhardt, J. Chem. Phys., 47 (1967) 1300;

C. Roetti and E. Clementi, J. Chem. Phys., 60 (1974) 4725.

13 P. A. Straub and A. D. McLean, Theor. Chim. Acta, 32 (1974) 227.

14 O. Gropen, S. Huzinaga and A. D. McLean, J. Chem. Phys., 73 (1980) 402; A. D. McLean, O. Gropen and S. Huzinaga, J. Chem. Phys., 73 (1980) 396.

15 E. A. Colbourn, J. M. Dyke, N. K. Farad and A. Morris, J. Electron. Spectrosc. Relat. Phenom., 14 (1978) 443.

16 D. C. Frost, C. A. McDonald and D. A. Vroom, J. Chem. Phys., 46 (1967) 4255.

17 M. S. Child and R. S. Bernstein, J. Chem. Phys., 59 (1973) 5916.

18 D. H. Rank, J. Opt. Soc. Am., 36 (1946) 239.

19 J. A. Coxon, Chem. Phys. Lett., 33 (1975) 136.

$20 \mathrm{~J}$. Wei and J. Tellinghuisen, J. Mol. Spectrose., 50 (1974) 317.

21 B. M. Rode, J. Chem. Soc., Faraday Trans. 2, 71 (1975) 481.

22 M. Schmeiser, W. Ludovici, D. Haumann and P. Sartori, Chem. Ber., 101 (1968) 4214 ; L. Stein, in V. Gutmann (Ed.), Halogen Chemistry, Academic Press, London, 1967, pp. $176-178$.

23 D. F. Smith, J. Chem. Phys., 21 (1953) 609.

24 D. W. Magnuson, J. Chem. Phys., 27 (1957) 223.

25 R. K. Heenan and A. G. Robiette, J. Mol. Struct., 55 (1979) 191.

26 R. K. Heenan and A. G. Robiette, J. Mol. Struct., 54 (1979) 135.

27 A. B. Altman, I. N. Mjaksin, V. F. Sukhoverkhov, G. V. Romanov and V.P. Spiridonov, Dokl. Akad. Nauk SSSR, 241 (1978) 360.

28 L. S. Bartell, M. J. Rothman and A. Gavezzotti, J. Chem. Phys., 76 (1982) 4136. 